\title{
PERCEPTIONS OF 9/11 AMONG COLLEGE-AGED STUDENTS, 2017-2019
}

\author{
AUDREY HEFFRON CASSERLEIGH \& REBECCA S. L. ROGERS \\ Emergency Management and Homeland Security Program, Florida State University, USA
}

\begin{abstract}
As Millennials have begun to age out of experiencing $9 / 11$ in the US and having tangible memories of the attack and its aftermath, a natural scepticism has grown surrounding the details of the event. The purpose of this survey was to understand perceptions of young adults $(\mathrm{N}=297)$ as they comprehend or remember the events of $9 / 11$ and details surrounding the attacks themselves. This survey seeks to understand the current perceptions of the events as they occurred by a Millennial student population. Independent variables include: (1) members of family in the military; (2) citizenship; (3) education; and (4) age at time of event. Dependent variables explore the following: perceptions of why the event occurred; who perpetrated the event; the involvement of the US Government; and truth and trust of media reporting. This is the first two years of a ten year longitudinal study. All survey respondents were between the ages of 20 and 22 at the time the survey was administered and enrolled in the college course "Introduction to Terrorism". Preliminary results indicate that a majority of respondents have inaccurate perceptions of the event and exhibit a high distrust of the US Governments' role in the attacks on 9/11 and how they came to be.
\end{abstract}

Keywords: Millennials, terrorism, 9/11, Government.

\section{INTRODUCTION}

This study is focused on understanding the current perceptions of the events of 11 September 2001 as they occurred by a Millennial student population at Florida State University (FSU). A literature review examining distrust of institutions, the influence of social media, and conspiracy theories will be presented followed by six hypotheses made by the researchers. Then the methods will be explained with sections on data collection, independent variables, dependent variables, and data analysis. Next, the results will be presented narratively and with appropriate tables, including notes on each specific hypotheses. The paper will close with a conclusion and reference page.

\section{LITERATURE REVIEW}

The current literature has a breadth of information regarding the attacks of 9/11 and how they have influenced current security in the USA and abroad. However, there exists a noticeable gap in the literature when it comes to the perceptions of the events by different populations. The following sections will examine the current body of knowledge surrounding the distrust of institutions (especially by youth populations), the influence of social media, and conspiracy theories.

\subsection{Distrust of institutions}

Current literature and research reveals that Millennials express low levels of confidence in nearly every American institution (Economic Innovation Group [1]). Millennials are born between the years of 1981 and 1996, with the youngest Millennials currently in their late teen years, and the oldest in their early 30s (Mitchell [2]).

Specifically, the report finds, "corporate America, Governors, and the news media inspire the lowest levels of confidence, with only one-fifth of Millennials placing a lot or a great deal 
of stock in them" (Mitchell [2]). Of 1,200 Millennials polled in a study by the Economic Innovation Group, they responded as having the least amount of confidence (defined as "some" or "very little") in the Federal Government (72\%), News Media (73\%), Governors (72\%) and Corporate America (72\%) (Economic Innovation Group [1]). Interestingly, colleges, universities and the military are the only institutions that garner the confidence of the majority of Millennials (Economic Innovation Group [1]). Millennials distrust of US Government is shown again in a Harvard study that asked young Americans (aged between 18 and 29 years old) how confident they were in the US judicial system (Institute of Politics [3]). Distrust in the US judicial system was $49 \%$; more specifically $35 \%$ said they had "not much confidence" and 14\% reported they had "no confidence" whatsoever (Institute of Politics [3]).

\subsection{Influence of social media}

One of the most striking differences between Millennials and older generations is that Millennials officially get more news from social media than watching actual news outlets or reading newspapers or other online news sources. A Pew Research Centre [2] study noted that $61 \%$ of respondents receive their news from Facebook and only $37 \%$ receive their news from traditional news sources such as television programming and online newspapers. This is in stark contrast to previous generations who utilize social media significantly less, with only $39 \%$ of Baby Boomers (those born after World War II) utilizing Facebook as a news source (Miller et al. [4]). This could be an element contributing to disjointed perceptions of events between Millennials and older generations.

This use of social media as a primary source for information can be fraught with problems including: (1) low accountability of journalists and publications; (2) a lack of fact based relevance; and (3) possible influence peddling (Shearer and Gottfried [5]). Social media is conversely aware of the influence it can have on its audience. Facebook, Twitter, and YouTube have experienced a 15\% increase in market influence between 2016 and 2017 (Shearer and Gottfried [5]).

Research also indicates Millennials are expressing unprecedented levels of social distrust. When asked the following question, "Generally speaking, would you say that most people can be trusted or that you can't be too careful in dealing with people", only 19\% of Millennials say most people can be trusted, compared with $40 \%$ of Baby-Boomers (Pew Research Center [6]). Millennials comfort with disbelief of facts related to the attacks on September 11th, 2001 can be partially explained by distrust in Government and mainstream media reporting, combined with an increased acceptance of conspiracy theories.

\subsection{Conspiracy theories}

Sunstein and Vermeule [7] define conspiracy theories as, "an effort to explain some event or practice by reference to the machinations of powerful people, who attempt to conceal their role". Similarly, Uscinski [8] define a conspiracy as a "secret arrangement between two or more actors to usurp political or economic power, violate established rights, hoard vital secrets, or unlawfully alter government institutions". They continue by stating that "a key point is that conspiracies speak to actual events that have occurred or are occurring" (Uscinski [8]).

Recent polls show that conspiratorial beliefs are not only common, but that most Americans believe in one conspiracy theory or another (Miller et al. [4]). Conspiracy theories surrounding 9/11 are prevalent, and, “...given the advances in information technology and 
social media, as well as individuals' tendencies to sort themselves into attitude-consistent silos, even ideas with little basis in fact have the potential to quickly spread unchecked" (Miller et al. [4]). Uscinski et al. [9] writes, "Many scholars have suggested that beliefs in specific conspiracy theories are the product of an underlying predisposition toward viewing events and circumstances as the product of conspiracy".

One of the most prominent conspiracy theories is the belief that the JFK assassination was coordinated by the US Government. In a 2001 poll, the Zogby Organization found that $68 \%$ of US citizens support the JFK assassination conspiracy (Kurtz [10]). Similar to conspiracies surrounding 9/11, the foundation of this conspiracy is a mistrust of the American Government and the belief in "widespread and systematic cover-up of critical evidence by various Government agencies" (Kurtz [10]).

Lasting conspiracy theories, such as the moon-landing hoax, have long-term consequences. One study found that exposure to information about the moon-landing conspiracy "resulted in greater endorsement of belief in moon landing conspiracy theories" (Jolley [11]). Exposure to conspiracy theories and belief in them can influence socio-political behaviour and result in widespread "negative attitudes towards powerful groups" and be a "significant predictor of prejudices" towards various dominant groups (Jolley [11]).

Of note, "Those who subscribe to conspiracy theories may create serious risks, including risks of violence" and the "existence of such theories raises significant challenges for policy and law" (Sunstein and Vermeule [7]). Some of the most common conspiracy theories surrounding 9/11 include: the crash in Shanksville, Pennsylvania was a missile and not an airplane, planned stock trades took place before the attacks to ensure certain individuals profited from the attacks, and that jet fuel cannot melt steel meaning the towers fell from a controlled demolition. Perceptions of $9 / 11$ events, and the prevalence of alternate theories, could heavily influence future security environments.

\section{HYPOTHESES}

The researchers in this study are embedded in a Millennial-rich environment while working on a large University campus with a diverse student population. The lead researcher is a terrorism expert with over 20 years of teaching in the field. Although it has been almost 20 years since the attacks, researchers, writers, filmmakers, and students seem to have taken more interest in the events that took place. This past year, was the first year that students who turned 18 had not been alive for $9 / 11$ and the researchers considered how this could impact the perception of those events.

The following hypotheses were formulated based on the current literature, the expertise of the lead researcher in the field, and guided the design of the study:

H1: A majority of college age students believe the US Government was involved in the 9/11 attacks in some way.

H2: College age students that have served in the military will believe the US Government had no knowledge of the 9/11 attacks.

H3: Male students are more likely to distrust current facts surrounding the events of $9 / 11$.

H4: Female students will be more likely to believe the number of deaths were in line with those reported by the media.

H5: Over time, age is going to influence the perceived role of the US Government in the attacks of $9 / 11$.

H6: Over time, age is going to influence the perception of those responsible for perpetrating the attacks. 


\subsection{Hypothesis connections}

\subsection{1 $\mathrm{H1} \rightarrow \mathrm{H} 5$ and $\mathrm{H} 6$}

As time continues, college aged students will become further and further removed from the 9/11 event which could influence how their "age" influences their perceptions of the US Government and perpetrators.

\subsection{2 $\mathrm{H} 2 \rightarrow \mathrm{H} 3$ and $\mathrm{H} 4$}

Over time, the number of students who have served in the military may increase or decrease, influencing the beliefs of male and female students. More specifically, a greater percentage of male than female students at FSU have served in the military. This could have an impact on their perceptions of the $9 / 11$ event.

\section{METHOD}

The following section will explain the method used by the researchers to conduct this research. Information regarding data collection, independent variables, dependent variables, and data analysis will be presented.

\subsection{Data collection}

\subsubsection{Population and setting}

In order to collect the data used in this inquiry, the researchers administered a survey titled "Perceptions of $9 / 11$ " on the first day of a large seminar class titled "Introduction to Terrorism". This class was chosen based because of its convenience for sampling, the age range of students, the high number of students consistently registered for the course, and the relative inexperience the students in the course have with the subject-matter. All surveys are anonymous and sorted by the research assistant each time they are disseminated. Students have the option to not complete the survey and ask any clarifying questions while taking the survey in class.

\subsubsection{Sample}

The goal is to have approximately 100 students complete the survey each semester over the course of 10 years to eventually develop a complex longitudinal study. The results in this paper are from the first year and a half, or three semesters, of data, with $\mathrm{N}=297$.

\subsection{Independent variables}

The independent variables were meant to provide a baseline, but also attempted to distinguish differences in a relatively homogenous population.

\subsubsection{Ethnicity}

In any given semester, minorities (any ethnicity other than Caucasian) present as less than $5 \%$ of the entire class. While ethnocentricities are not currently surveyed in the independent variables, this is a possible modification for future studies and is important to note before presenting the results.

\subsubsection{Age of respondents}

This longitudinal survey captures the age of the respondent at the time of the survey, and the age of the respondent during 9/11, resulting in the provision of both stagnant and variable data. Age at time of survey will likely remain constant over time as most college age students 
are between 18 and 22 years of age. Currently the average age of all respondents is 21 at the time of the survey.

Eventually, age at time of 9/11 will move from a positive to a null number. In a few years, college age students will not yet have been born when the $9 / 11$ event occurred. The average age of the respondents during the 9/11 event is 4.5 years of age, suggesting a limited observational ability. It can be reasonably assumed age 4.5 was too young to have full situational awareness during the 9/11 event and its aftermath.

\subsubsection{Gender of respondents}

Gender was coded in as male, female, and other. Of the $\mathrm{N}=297$ respondents 140 identified as male, 152 identified as female, 1 identified as other, and 4 declined to answer the question. Of the respondents who chose to identify their gender in a binary manner (either male or female) $48 \%$ were male and $52 \%$ were female, representing a balanced response.

\subsubsection{College level of students}

This survey was administered to an upper level undergraduate course, registered at the 4,000 level, the highest level in the undergraduate suite of classes. FSU, where the class and survey were administered, is a very large, public university in the southeast United States. Total undergraduate enrolment as of Spring 2019 at FSU is 31,257. The independent variable that asked for years in college yielded a range of answers from 0.5 to 5 , with the average years in college calculated at 2.9. Since this survey was administered in an upper division course, this average seems appropriately reflective of the experience of the respondents as juniors or seniors in college.

\subsection{Dependent variables}

The survey questions were developed by the lead researcher and research assistant and were based on the main factors they hypothesized would impact a student's perception of the event. The current literature and the expertise of the lead researcher were considered when developing the survey questions. The survey tool gave respondents the option to mark multiple answers, allowing them to pick more than one in each of the dependent variable areas.

\subsubsection{Who perpetrated the event?}

The first category of dependent variable asked the respondents about who they believed perpetrated 9/11. They were able to choose multiple options including "Terrorists", "The US Government", "Foreign Governments", or "Other". These variables were coded as 9/11 PerpTer, 9/11 Perp-US Govt, 9/11 Perp-Foreign Govt, 9/11 Perp-Other.

\subsubsection{Why the attacks occurred}

The second category of dependent variable examined the reason 9/11 happened. Respondents were allowed to select multiple options including "Terrorists wanted to target America", "the President needed an excuse to go to war", "The President wanted to re-elected", and "Other". These variables were coded as 9/11 Due to: Terrorists, 9/11 Due to: War Excuse, 9/11 Due to: Re-election, 9/11 Due to: Other.

\subsubsection{Death perceptions of the attacks}

The third category of dependent variables sought to examine perceptions of deaths in 9/11. The respondents were asked if they believed the deaths were "As was reported by the US Government", "Higher than was reported", "Lower than was reported", "Zero deaths", or 
"Other". These variables were coded as 9/11 Deaths: Reported-US Govt, 9/11 Deaths: Higher, 9/11 Deaths: Lower, 9/11 Deaths: Zero, 9/11 Deaths: Other.

\subsubsection{The role of the US Government}

The fourth category of dependent variables sought to understand the role the US Government played in 9/11, as understood by the respondents. The survey asked if the US Government had, "No prior knowledge", "Some prior knowledge", "Some prior knowledge, but did nothing", "Some prior knowledge and encouraged it", "The US Government perpetrated 9/11", and "Not sure". These variables were coded as, US Govt: No prior knowledge, US Govt: Some prior knowledge, US Govt: Prior knowledge/did nothing, US Govt: Prior knowledge/encouraged it, US Govt: Did 9/11, US Govt: Not sure.

An example of the survey questionnaire is shown in Fig. 1.

\subsection{Data analysis}

Because the data is only representative of one and a half years of a 10 year study, the researchers used basic statistical analysis to answer each of the hypothesized responses. Each

I believe the $9 / 11$ event was perpetrated by:
a. Terrorists
b. US Government
c. Foreign Governments
d. Other

I believe the 9/11 attacks happened because:
a. Terrorists wanted to target the US
b. The US Governments needed an excuse to go to war
c. The US President at the time wanted to get re-elected
d. Other

I believe the direct deaths from $9 / 11$ were:
a. 2,996 people, as was reported
b. A higher number than was reported
c. A lower number than was reported
d. Zero people
e. Other

I believe the US Government:

a. Had no prior knowledge of $9 / 11$

b. Had some prior knowledge of $9 / 11$

c. Had prior knowledge of $9 / 11$ but did nothing about it

d. Had prior knowledge of 9/11 and encouraged it

e. Conducted the $9 / 11$ event

f. Not sure

g. Other

Figure 1: Perceptions of 9/11 survey example. 
survey was analysed by asking whether the respondent answered "Yes" or "No" to each of the question answers. If a respondent answered that the 9/11 event was perpetrated by terrorists, "perpetrated by terrorists" would receive a "Y" and "perpetrated by US Government", "perpetrated by Foreign Governments", and "perpetrated by other" would be marked "N". From here, individual charts were created to tabulate the results of each question asked and each answer received. A simple percentage was calculated to determine how each student responded to the survey (i.e. "_ \% of students believe that $9 / 11$ was perpetrated by terrorists"). The goal is to use these baseline percentages to track patterns and changes that occur over the years as students age further and further away from the events on 9/11.

\section{RESULTS}

The first question that truly gets at the heart of any 9/11 conspiracy belief is: "Who perpetrated the 9/11 attacks?" By asking the respondents who was culpable the plan was to identify schisms in perceptions of responsibility (Table 1).

This initial question and the results seem in line with mainstream thinking that 9/11 was perpetrated by terrorists. These dependent variables show no statistical significance when measured against any of the independent variables including age, gender, or exposure to service in the military.

The second set of questions gets at motivation by asking why the 9/11 event occurred. The results in Table 2 are in line with mainstream thinking that excludes any internal motivation on the part of US leadership.

Interestingly, while most respondents did not choose the popular conspiracy theory that President Bush wanted to be elected, we do begin to see a possible eschewing of mainstream beliefs in the selection of the "Other" category. Respondents were given an open answer opportunity at the end of the survey, but the open ended answers predominately reflected questions that were already asked. For example, one respondent wrote, "I believe it was a

Table 1: “I believe the 9/11 event was perpetrated by...". Where $N \neq 297$ some respondents did not answer or answers were unclear.

\begin{tabular}{|l|c|c|c|c|}
\hline Responses & $\begin{array}{c}\text { Perpetrated } \\
\text { by terrorists } \\
(1 \mathrm{a})\end{array}$ & $\begin{array}{c}\text { Perpetrated by } \\
\text { US Government } \\
(1 \mathrm{~b})\end{array}$ & $\begin{array}{c}\text { Perpetrated by } \\
\text { Foreign } \\
\text { Governments } \\
(1 \mathrm{c})\end{array}$ & $\begin{array}{c}\text { Perpetrated } \\
\text { by Others } \\
(1 \mathrm{~d})\end{array}$ \\
\hline $\mathrm{N}=$ Yes & 281 & 31 & 37 & 9 \\
\hline $\mathrm{N}=$ No & 15 & 266 & 260 & 288 \\
\hline Percentage Yes & $94.6 \%$ & $10.5 \%$ & $12.45 \%$ & $3 \%$ \\
\hline Percentage No & $5.4 \%$ & $89.5 \%$ & $87.55 \%$ & $97 \%$ \\
\hline
\end{tabular}

Table 2: "I believe the 9/11 attacks happened because...".

\begin{tabular}{|l|c|c|c|c|}
\hline Responses & $\begin{array}{c}\text { Terrorists } \\
\text { wanted to target } \\
\text { the US } \\
(2 \mathrm{a})\end{array}$ & $\begin{array}{c}\text { The US Government } \\
\text { needed an excuse to } \\
\text { go to war } \\
(2 \mathrm{~b})\end{array}$ & $\begin{array}{c}\text { The US President } \\
\text { at the time wanted } \\
\text { to get re-elected } \\
(2 \mathrm{c})\end{array}$ & $\begin{array}{c}\text { Other } \\
(2 \mathrm{~d})\end{array}$ \\
\hline $\mathrm{N}=$ Yes & 258 & 51 & 9 & 19 \\
\hline $\mathrm{N}=$ No & 39 & 246 & 288 & 278 \\
\hline Percentage Yes & $86.8 \%$ & $17.2 \%$ & $3 \%$ & $6 \%$ \\
\hline Percentage No & $13.2 \%$ & $82.8 \%$ & $97 \%$ & $94 \%$ \\
\hline
\end{tabular}


combination of President Bush wanting to get re-elected and foreign terrorists supported by Foreign Governments. I think they knew about each other". When the variables $2 b, 2 c$, and $2 \mathrm{~d}$ are combined it reveals that $26.2 \%$ of the respondents believed there was an internal influencing factor that led to the events on $9 / 11$.

When asked about the number of death attributed to the $9 / 11$ event students were asked to choose one of the following answers. In some cases multiple answers were selection so $\mathrm{N}=308$ for this DV.

Table 3 reveals that respondents have mistrust about the number of death reported, with $44 \%$ indicated they believe there were a higher number of deaths than was reported. Of greatest relevance is that $48 \%$ of the respondents don't believe the numbers as they were reported. This may tie back to the research on distrust in the media (Miller et al. [4], Tang et al. [12]). Is it that Millennials distrust the media reporting? That they feel the Government was dishonest about the number of deaths? Or something else? This is something the researchers want to try and further understand in future surveys.

Table 3: "I believe the direct deaths from 9/11 were...".

\begin{tabular}{|l|c|c|c|c|c|}
\hline Responses & $\begin{array}{c}2,996 \text { people, } \\
\text { as was reported } \\
(3 \mathrm{a})\end{array}$ & $\begin{array}{c}\text { A higher } \\
\text { number than } \\
\text { was reported } \\
(3 \mathrm{~b})\end{array}$ & $\begin{array}{c}\text { A lower number } \\
\text { than was reported } \\
(3 \mathrm{c})\end{array}$ & $\begin{array}{c}\text { Zero } \\
\text { people } \\
(3 \mathrm{~d})\end{array}$ & $\begin{array}{c}\text { Other } \\
(3 \mathrm{e})\end{array}$ \\
\hline $\mathrm{N}=$ Yes & 154 & 135 & 13 & 0 & 6 \\
\hline Percentage Yes & $50 \%$ & $44 \%$ & $4 \%$ & $0 \%$ & $2 \%$ \\
\hline
\end{tabular}

The fourth category of dependent variables begins to get at the knowledge or participation by the US on the $9 / 11$ event.

Table 4 begins to reveal perceptions of culpability of the part of the US Government. $84.2 \%$ of the respondents do not believe the US Government was unaware that 9/11 was going to happen. However, when asked the reverse, if they believe the US Government had some prior knowledge, only $39.4 \%$ of the respondents answered in the affirmative. When asked specifically about knowledge of the attacks before they happened, the respondents had even less support for the idea of the Government having prior knowledge. What becomes more interesting is when variables are grouped into larger influence categories. When variables $4 \mathrm{a}(39.4 \%), 4 \mathrm{~b}(26.6 \%), 4 \mathrm{c}(3.4 \%)$, and $4 \mathrm{~d}(3.3 \%)$ are combined, we see that $72.7 \%$ of the respondents believed the US Government had some prior knowledge of the $9 / 11$ event.

\subsection{Specific hypotheses}

The results regarding H1: A majority of college age students believe the US Government was involved in the $9 / 11$ attacks in some way, were found to be a positive number. Over $70 \%$ of the respondents felt the US Government had some role in the 9/11 event.

The second hypothesis, H2: College age students that have served in the military will believe the US Government had no knowledge of the 9/11 attacks was not proven, because the numbers of prior service member in the survey pool was insignificant.

With regard to H3: Male students are more likely to distrust current facts surrounding the events of $9 / 11$ it turns out there is no statistical difference between the perceptions of male versus the perceptions of females. Both genders indicated a high distrust of facts regarding number of dead, and both genders equally believed the US Government had played a role in 


\begin{tabular}{|c|c|c|c|c|}
\hline$\stackrel{\vec{D}}{\overrightarrow{0}} \stackrel{00}{ \pm}$ & $\infty$ & $\begin{array}{l}\infty \\
\text { N }\end{array}$ & $\begin{array}{l}\dot{0} \\
\dot{b} \\
i\end{array}$ & 守. \\
\hline 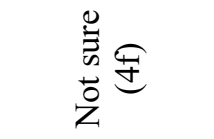 & $\approx$ & $\underset{⿱}{\stackrel{ \pm}{*}}$ & $\stackrel{\circ}{\stackrel{2}{r}}$ & ๙ें \\
\hline 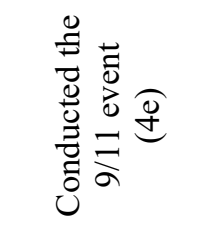 & 이 & $\mid \begin{array}{c}\infty \\
\infty\end{array}$ & ले & $\frac{2^{\circ}}{0^{\circ}}$ \\
\hline 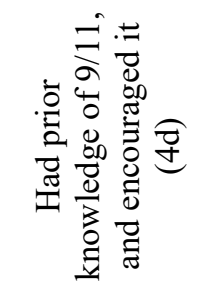 & 으 & $\begin{array}{c}\infty \\
\infty \\
\sim\end{array}$ & $\stackrel{\stackrel{\circ}{+}}{\stackrel{0}{m}}$ & $\begin{array}{l}\stackrel{\partial}{0} \\
\text { \&̊ }\end{array}$ \\
\hline 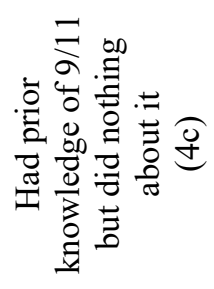 & 2 & $\frac{\infty}{\sim}$ & $\begin{array}{l}\text { bे } \\
\dot{b} \\
\text { iे }\end{array}$ & $\stackrel{\stackrel{\partial}{q}}{\stackrel{p}{r}}$ \\
\hline 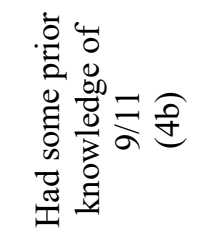 & $\Xi$ & $\stackrel{\infty}{-}$ & $\begin{array}{l}\stackrel{+}{+} \\
\stackrel{\text { mे }}{ }\end{array}$ & $\begin{array}{l}\dot{b}_{0}^{0} \\
\dot{8}\end{array}$ \\
\hline 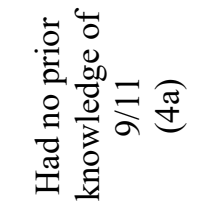 & $\hat{\gamma}$ & 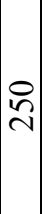 & $\begin{array}{l}\partial^{0} \\
\infty \\
i \\
\end{array}$ & $\stackrel{\stackrel{\circ}{+}}{\stackrel{+}{\infty}}$ \\
\hline 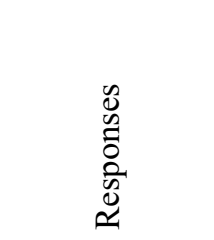 & $\begin{array}{l}\tilde{0} \\
2 \\
11 \\
z\end{array}$ & $\begin{array}{c}0 \\
Z \\
11 \\
Z\end{array}$ & $\begin{array}{l}\infty \\
0 \\
0 \\
0 \\
0 \\
0 \\
0 \\
0 \\
0 \\
0 \\
0\end{array}$ & 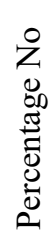 \\
\hline
\end{tabular}


the 9/11 attacks. Females were just as likely to distrust the facts, like number of reported dead, as males, lending no support to H4: Female Students will be more likely to pick the number of deaths as reported.

The two hypotheses that are designed to evaluate change over time cannot yet be evaluated. More longitudinal data will be required to examine H5: Over time, age is going to influence the perceived role of the US Government and H6: Over time, age is going to influence perception of perpetrators.

\section{CONCLUSION}

As Millennials grow up further away from the events of 9/11, the disbelief of facts surrounding the event are expected to grow. As the study continues, the researchers expect to see more disconnect between the facts that were released and the perception of those facts by the Millennial generation (and eventually Gen Z). This preliminary analysis shows that there is valuable analysis that can be done to understand the distrust of Government and media by younger generations.

The data aggregated in this paper is only a small sample of what will eventually be a larger pool of responses. Future analysis will evaluate multi collinear probabilities looking for more significant relationships between the variables.

\section{REFERENCES}

[1] Economic Innovation Group, The Millennial economy: Findings from a new EY and EIG national survey of Millennials, EIG: Washington DC, 2016.

[2] Mitchell, A., Millennials and Political News, Pew Research Center, 2015.

[3] Institute of Politics, No front-runner among prospective republican candidates, Hillary Clinton in control of Democratic Primary, Harvard youth poll finds, Harvard Kennedy School: Boston, 2016.

[4] Miller, J.M., Saunders, K.L. \& Farhart, C.E., Conspiracy endorsement as motivated reasoning: The moderating roles of political knowledge and trust. American Journal of Political Science, 60(4), pp. 824-844, 2015.

[5] Shearer, E. \& Gottfried, J., News Use Across Social Media Platforms 2017, Pew Research Center, 2017.

[6] Pew Research Center, Millennials in adulthood: Detached from institutions, networked with friends, 2014. www.pewsocialtrends.org/2014/03/07/millennials-in-adulthood/.

[7] Sunstein, C. \& Vermeule, A., Conspiracy theories: Causes and cures. Journal of Political Philosophy, 17(2), pp. 202-227, 2008.

[8] Uscinski, J.E., American Conspiracy Theories, Oxford University Press: Oxford, 2014.

[9] Uscinski, J.E., Klofstad, C. \& Atkinson, M.D., What drives conspiratorial beliefs? The role of informational cues and predispositions. Political Research Quarterly, 69(1), pp. 57-71, 2016.

[10] Kurtz, M.L., The JFK Assassination Debates: Lone Gunman Versus Conspiracy, University Press of Kansas, 2006.

[11] Jolley, D., The detrimental nature of conspiracy theories. Psychology Postgraduate Affairs Group Quarterly, 88, pp. 35-39, 2013.

[12] Tang, J., Hu, X. \& Liu, H., Is distrust the negation of trust? The value of distrust in social media. Conference Proceedings of Hypertext 2014, Santiago, Chile, 2014. 